Disponível em:

http://editora.unoesc.edu.br/index.php/race

RACE, Joaçaba, v. 16, n. 2, p. 703-728, maio/ago. 2017

\title{
MAL-ESTAR NAS ORGANIZAÇÕES: POR QUE OS JOVENS ESTÃO ABANDONANDO O MUNDO CORPORATIVO?
}

Unrest in organizations: why are young people dropping out the corporate world?

\begin{abstract}
Ana Heloisa da Costa Lemos
E-mail: aheloisa@iag.puc-rio.br

Doutora em Sociologia pelo Instituto Universitário de Pesquisas do Rio de Janeiro; Mestre em Administração pela Fundação Getúlio Vargas; Professora nos cursos de Graduação, Mestrado e Doutorado da Pontifícia Universidade Católica do Rio de Janeiro; Coordenadora do MBA em Gestão de Recursos Humanos da Pontifícia Universidade Católica do Rio de Janeiro. Endereço para contato: Rua Marquês de São Vicente, 225, Gávea, 22430-060, Rio de Janeiro, Rio de Janeiro, Brasil.

Mariana Soares Pinto

E-mail: mrsoarespinto@gmail.com Graduanda em Administração de Empresas e bolsista de Iniciação Científica pela Pontifícia Universidade Católica do Rio de Janeiro.

Marcelo Almeida de Carvalho Silva

E-mail: marceloacs@hotmail.com Mestre em Administração de Empresas pela Pontifícia Universidade Católica do Rio de Janeiro; Doutorando em Administração de Empresas pela Pontifícia Universidade Católica do Rio de Janeiro.
\end{abstract}

Artigo recebido em 05 de agosto de 2015. Aceito em 28 de novembro de 2016. 


\section{Resumo}

Ocrescimento da rotatividade da força de trabalho brasileira nos últimos anos, em especial de suas camadas mais jovens, vem sendo motivo de preocupação de empresários e governantes. Causa de prejuízos para toda a sociedade, a alta rotatividade dos jovens é comumente explicada pela questão geracional, sendo o comportamento fugaz desses profissionais combinado a aspirações como autonomia, qualidade de vida e flexibilidade, as supostas razões para a constante troca de emprego. Contudo, muitos desses jovens fazem essa migração reiniciando suas carreiras como servidores públicos, docentes ou empreendedores, o que sugere, também, uma rejeição às carreiras nas grandes empresas privadas. Dessa maneira, neste artigo propôs-se investigar as razões que vêm afastando jovens de empresas privadas tradicionais, levando-os a abdicarem do trabalho nessas empresas para recomeçarem suas vidas profissionais em outras bases. Para atingir esse objetivo foram entrevistados 12 profissionais que já fizeram essa migração, cujas entrevistas foram analisadas por meio da análise de conteúdo. Os resultados sugerem que, contrariando parte da literatura que homogeneíza esses jovens, não há um perfil único dentro da mesma geração e essas diferenças impactam as decisões de carreira desses indivíduos. Todavia, algumas caracterizações presentes nessa mesma literatura foram corroboradas pelos achados da presente pesquisa. Ademais, o sentido do trabalho, aspecto pouco mencionado na referida literatura, emergiu como importante fator que afasta o jovem da carreira tradicional.

Palavras-chave: Geração Y. Rotatividade. Sentido do trabalho. Carreira.

\section{Abstract}

The growth of the turnover of the Brazilian workforce in recent years, especially of its younger generation, has been of concern to entrepreneurs and government. This issue, which causes losses for the whole society, is commonly explained by the generational issue, and the elusive behavior of these professionals is combined with aspirations to autonomy, quality of life and flexibility, the alleged reasons for the constant exchange of employment. However, many of these young people do this migration restarting their careers as public employees, teachers or entrepreneurs, and it also suggests a rejection of careers in big private companies. Thus, this article aimed to investigate the reasons why young people are steping away from traditional private businesses, leading them to abdicate the work in these companies for restarting their professional lives in other bases. To achieve this goal were interviewed 12 professionals who have made this migration, whose interviews were analyzed using content analysis. The results suggest that, contrary to some of the literature that homogenizes these young people, there is no single profile within the same generation and these differences impact on the career decisions of these individuals. However, some characterizations present in this same literature were corroborated by the findings of this research. Besides, the meaning of work, aspect little mentioned in this literature, emerged as an important factor that separates the young people from the traditional career.

Keywords: Generation Y. Turnover. Meaning of labor. Career. 


\section{INTRODUÇÃO}

Em março de 2014, o Ministério do Trabalho e Emprego promoveu seminário sobre rotatividade no Mercado de Trabalho. Com o intuito de discutir propostas de combate ao crescimento desse indicador - que chegou a uma taxa de 63,7\% em 2013 -, o seminário contou com a presença de trabalhadores e empregadores, além do governo. ${ }^{11}$ Tal fato revela a preocupação com um fenômeno crescente no mercado de trabalho brasileiro, a elevada rotatividade de sua força de trabalho, com danos para toda a sociedade. Esse fenômeno traz às empresas os custos associados à captação, seleção, contratação e treinamento de novos empregados. Os trabalhadores, por sua vez, são impactados pela alta de preços, na medida em que as empresas repassam para os consumidores os custos decorrentes do turn-over, além de sofrerem a sensação de insegurança proveniente da possibilidade de ficarem desempregados (DEPARTAMENTO INTERSINDICAL DE ESTATÍSTICA E ESTUDOS SOCIOECONÔMICOS, 2014). Ao Governo Federal cabe arcar com os elevados custos do seguro-desemprego, efeito secundário desse processo. Por isso, o aumento da taxa de rotatividade afeta todos os atores que se relacionam no mercado de trabalho.

Segundo dados do Departamento Intersindical de Estatística e Estudos Socioeconômicos (2014), a taxa de rotatividade no Brasil era, em 2003, de 52,4\%, chegando a 64,5\% em 2011 e atingindo os já mencionados 63,7\% em 2013. Ainda de acordo com o Departamento Intersindical de Estatística e Estudos Socioeconômicos, na última década $45 \%$ dos desligamentos ocorreram com menos de seis meses de trabalho e 65\% com menos de um ano. Apesar de esses números representarem todos os tipos de desligamento (por decisão do empregador, empregado ou outro motivo), quando se considera a taxa de rotatividade com base apenas nos desligamentos a pedido do trabalhador, os números também apresentam crescimento: de 2002 a 2013 essa taxa aumentou 60\%, saindo de 15,6\% em 2002 e chegando a 25\% em 2013 (DEPARTAMENTO INTERSINDICAL DE ESTATÍSTICA E ESTUDOS SOCIOECONÔMICOS, 2014).

De forma geral, considerando todos os tipos de desligamentos, há uma concentração desse aumento nas pessoas entre 18 e 24 anos, com aumento significativo quando ampliado até 29 anos. Esse dado é corroborado pelo estudo sobre rotatividade dos jovens no mercado de trabalho formal brasileiro, divulgado pelo Instituto de

\footnotetext{
${ }^{1}$ Informações do Ministério do Trabalho.
} 
Pesquisas Econômicas Aplicadas (CORSEUIL et al., 2013). Segundo o documento, a taxa de rotatividade dos jovens é quase o dobro da dos trabalhadores adultos, bem como o desligamento voluntário, cuja participação é 1,33 vez maior entre os mais jovens do que entre os mais maduros.

Uma possível explicação para esse fenômeno aponta para a questão geracional, sugerindo que os indivíduos pertencentes à denominada Geração Y (nascidos entre 1980 e 2000) seriam mais inclinados à troca de emprego em decorrência de sua propensão à mudança, inquietação e até insubordinação (VELOSO; SILVA; DUTRA, 2012). Nesse sentido, a alta rotatividade dos jovens seria explicada pela facilidade com que eles se desfazem dos empregos em favor de novas perspectivas que lhes pareçam mais atraentes. Essas perspectivas, de acordo com a literatura, incluem aspectos como busca por autonomia, flexibilidade temporal e espacial, comunicação aberta, feedback contínuo, hierarquia menos rígida e prazer no trabalho (CAVAZOTTE; LEMOS; VIANA, 2012). Assim, em razão das suas características, aqueles pertencentes a essa geração parecem transitar entre diversas organizações, de acordo com o cenário que se desenhe mais favorável, sem demonstrar vínculos de lealdade. Por esse motivo, atrair, reter, motivar e comprometer esses jovens apresentam-se como grandes desafios para as empresas (PERRONE et al., 2013). Contudo, é importante destacar que esses estudos possuem em comum o fato de trabalharem com uma perspectiva aspiracional desses jovens, apresentando resultados baseados na vontade declarada dos entrevistados, sem problematizar, no entanto, as diferenças entre o desejo e a ação de procurar uma posição que ofereça as condições almejadas.

Paralelamente, é possível observar que a busca por condições de trabalho convenientes não se limita à troca de empresas, manifestando-se também por meio de trocas mais radicais, como a mudança de carreira. Nesse sentido, alguns estudos apontam para o êxodo de profissionais de empresas privadas tradicionais em direção ao ambiente acadêmico (KILIMNIK et al., 2009; OLIVEIRA; KILIMNIK; DE OLIVEIRA, 2013), ao setor público (CÔRTES; SILVA, 2006; EICHLER; LEMOS; NEVES, 2014) e profissionais que abandonam seus empregos para empreender (SILVA, 2008; BEYDA; CASADO, 2011).

A observação desses dois fenômenos - alta rotatividade dos jovens e migração de profissionais para outros setores e empresas - motivou questionamentos que originaram a presente pesquisa, em que se teve o objetivo de compreender as razões que levaram jovens profissionais a rejeitarem seus empregos em empresas privadas tradicionais, abdicando de suas carreiras e optando por reiniciar suas vidas profissionais nos setores acadêmico ou público ou em sua própria empresa. Para atingir tais 
objetivos foram entrevistados jovens que puseram em prática o desejo de mudar de carreira em busca de condições que julgaram mais favoráveis. O estudo desse grupo ofereceu a oportunidade de entender o comportamento desses jovens identificando, em suas motivações, possíveis aproximações ou afastamentos das aspirações profissionais dos "Yrs", abordadas em pesquisas anteriores. Pretendeu-se, assim, mapear pontos de insatisfação vivenciados pelos jovens nas empresas.

Com isso, este estudo torna-se relevante por contribuir para a pesquisa acadêmica em dois pontos: investigar as motivações de jovens que efetivamente abandonaram seus empregos visando atender aos seus interesses, não se limitando, portanto, a especular acerca de suas intenções; e considerar a nova opção de carreira desse profissional. Acredita-se que esses dois pontos possam suportar debates sobre o movimento de migração desses jovens.

Como contribuição para as empresas, acredita-se que nesta pesquisa se poderá fornecer informações que, ao ajudarem a entender os motivos das saídas desses jovens do mundo corporativo, possam auxiliar as empresas a delinearem políticas capazes de atrair e reter esses profissionais.

Para apresentar os achados da pesquisa em questão estruturou-se o presente artigo em cinco seções, incluindo esta introdução. A segunda seção é dedicada a discutir a literatura recente sobre a Geração Y - referência teórica inicial deste trabalho - bem como sobre os sentidos do trabalho, dado que esse tema apareceu, de forma recorrente, nos relatos obtidos. Na terceira são abordados os aspectos metodológicos da pesquisa. Na quarta seção são analisados os resultados e, na última, apresentadas as considerações finais.

\section{REFERENCIAL TEÓRICO}

\subsection{A GERAÇÃO Y}

As organizações contemporâneas têm enfrentado o desafio constante de captar e, principalmente, reter jovens profissionais qualificados, considerados menos leais do que seus antecessores. Esse desafio tem sido constantemente atribuído à questão geracional, decorrente das mudanças de valores e expectativas dos nascidos entre 1980 e 2000, a chamada Geração Y (ALSOP, 2008). Para compreender essa questão, diversas pesquisas têm sido desenvolvidas com vistas a mapear a transformação de valores e comportamentos dos trabalhadores, de acordo com as mudanças geracionais. Para Smola e Sutton (2002), as gerações são caracterizadas como um grupo de 
indivíduos nascidos no mesmo espaço de tempo, possuindo vivências históricas e sociais comuns que afetam a maneira de reagirem às situações.

Entre as suas características, a literatura destaca o fato de serem jovens dinâmicos e que estão sempre em busca de novos desafios nas organizações. Quando comprometidos com uma tarefa que julgam interessante e que lhes trará aprendizado, tendem a desempenhá-la com excelência, entretanto, a partir do instante que deixam de enxergar oportunidades em seu emprego, não temem em migrar de empresa. Essa nova geração preza por flexibilidade e autonomia nas organizações, além de querer um ambiente descontraído e amigável, feedback constante, participação nas decisões e mais proximidade das chefias (TULGAN, 2009; ALSOP, 2008; CENNAMO; GARDNER, 2008).

Outro aspecto apontado pela literatura sobre esses jovens diz respeito à sua ligação com a tecnologia, estando conectados em todos os momentos do dia. Esses indivíduos também são descritos como ambiciosos, confiantes, imediatistas e impacientes, querendo sempre acelerar o desenvolvimento de sua carreira, não temendo a rotatividade de empregos (VASCONCELOS et al., 2010). Contudo, não lidam bem com restrições e frustrações, o que leva a um comportamento inquieto, contestador e, por vezes, insubordinado, que pode criar o ambiente ideal para a mudança, considerando a maior propensão que apresentam para mudar de emprego (LIPKIN; PERRYMORE, 2010; VELOSO; SILVA; DUTRA, 2012).

Em razão da sua criação, repleta de feedbacks de seus pais, os "Yrs” gostam de saber como está o seu desempenho no trabalho e necessitam de premiações constantes, como aumentos de salário e promoções. Por mais que não queiram ter apenas retribuições financeiras em seus empregos, esses indivíduos também buscam ter um padrão de vida elevado. Para esses jovens, o trabalho deve ser uma parte prazerosa de seu dia, uma vez que eles dedicarão grande parte do seu tempo a ele. Mesmo sendo caracterizados como pessoas mais individualistas, os “Yrs” também gostam de trabalhar em grupo, desde que a tarefa seja de seu agrado. Entretanto, por mais que gostem do que fazem dentro das empresas, essa geração também possui diversos interesses fora do ambiente de trabalho e atribuem à sua vida pessoal um grande valor e estão em busca de qualidade de vida. Essa geração também é preocupada com aspectos socioambientais, envolvendo-se com projetos relacionados a esses assuntos (ERICKSON, 2008; LIPKIN; PERRYMORE, 2010).

Pesquisas nacionais recentes (CAVAZOTTE, LEMOS; VIANA, 2012; SÁ; LEMOS; CAVAZOTTE, 2014) trazem a compreensão dos desejos e valores desses jovens, comparando-os com os das gerações anteriores. Os estudos destacam aspectos 
que vão ao encontro de pontos correntemente abordados na literatura internacional que caracterizam tal geração, como a busca constante por prazer no ambiente de trabalho, o desejo por flexibilidade, a necessidade de ter bons relacionamentos interpessoais e uma maior preocupação com os aspectos ligados à responsabilidade social. Entretanto, as autoras também destacam pontos que aproximam a Geração Y das anteriores, como a busca por crescimento em uma mesma organização, o desejo por estabilidade e a expectativa por um bom salário. Outro aspecto ressaltado diz respeito à heterogeneidade de respostas entre os entrevistados em certos tópicos. Esse fator revela que, mesmo a pesquisa tendo sido realizada com um grupo com características homogêneas em termos de nível socioeconômico e de escolaridade, foram identificadas diferenças marcantes entre os entrevistados. Dessa maneira, pode-se concordar com as críticas feitas por Lemos (2012) e Oliveira, Piccinini e Bitencourt (2012) às generalizações feitas pela literatura relacionada à Geração Y, a qual trata esse grupo como um bloco homogêneo, sem considerar suas diferenças econômicas, sociais e culturais. Sem tal diferenciação, chega-se a uma perspectiva de uma geração ocidental de “jovens bem-nascidos e bem-educados” (LEMOS, 2012, p. 2), sem se considerarem os subgrupos dessa população. Dessa maneira, segundo a autora, os dados apresentados pela literatura referentes à essa nova geração, apesar de importantes para uma compreensão geral da mudança de perspectivas entre as gerações, devem ser lidos com cuidado, evitando-se as generalizações.

\subsection{O SENTIDO DO TRABALHO}

Conforme mencionado anteriormente, o sentido do trabalho não era, inicialmente, o escopo desta pesquisa. Contudo, a recorrência com que esse tema emergiu da fala dos entrevistados indicou sua relevância para a compreensão do comportamento desses jovens no mercado de trabalho. Esse fato exigiu dos pesquisadores a revisão da literatura sobre o sentido do trabalho de forma a suportar a discussão com a fala dos entrevistados.

Diversos estudos a respeito do sentido do trabalho procuram, como ponto de partida, a distinção entre os termos sentido e significado (ROSSO; DEKAS; WRZESNIEWSKI, 2010; ANDRADE; DA ROSA; DELLAGNELO, 2012; TOLFO; PICCININI, 2007). De forma geral, esses estudos sugerem que o significado do trabalho seria fruto de uma construção coletiva, relacionada à uma determinada circunstância histórica e social, enquanto o sentido é produzido individualmente e depende da compreensão de cada indivíduo. Apesar disso, os trabalhos acadêmicos constantemente confundem os termos (ROSSO; DEKAS; WRZESNIEWSKI, 2010) ou mesmo os 
tratam como sinônimos (TOLFO; PICCINNI, 2007). Rosso, Dekas e Wrzesniewski (2010) sugerem que o termo significado (meaning) pode ser aplicado na tentativa de distinção entre os diversos tipos de significados que um trabalho pode assumir, enquanto o sentido (meaningful ou meaningfulness) serviria como medidor da quantidade de significado que um indivíduo atribui ao trabalho. Sem a pretensão de exaurir a discussão a respeito do tema, nesta pesquisa adota-se a concepção de Rosso, Dekas e Wrzesniewski (2010) que consideram o significado como algo associado a interpretações socialmente compartilhadas sobre o trabalho, e o sentido, como algo individual.

A falta de consenso acerca desses termos indica a complexidade de se abordarem os sentidos e significados do trabalho como temas de pesquisa. Além de sua complexidade, o sentido do trabalho é um fenômeno dinâmico e multidimensional, que pode ser oriundo de diferentes fontes como valores, motivações, crenças, interações e tarefas, variando em importância para cada indivíduo (ROSSO; DEKAS; WRZESNIEWSKI, 2010). Essa multidimensionalidade é reforçada em diversos estudos que procuram descrever essas dimensões e como elas podem atribuir sentido ao trabalho (OLIVEIRA et al., 2004; MORIN; TONELLI; PLIOPAS, 2007; ROSSO; DEKAS; WRZESNIEWSKI, 2010). Oliveira et al. (2004) argumentam que o trabalho possui três dimensões principais - individual, organizacional e social - divididas em subdimensões. De acordo com os autores, uma das dimensões que serve de fonte de sentido para o trabalho é a clareza em relação aos seus objetivos. Assim, saber a razão da execução de determinada tarefa é importante para que o trabalho seja percebido como algo provido de sentido. A realização de tarefas sem propósito ou cujo propósito é desconhecido alienam o trabalhador, que passa a se sentir incapaz de atribuir sentido à atividade e, consequentemente, ao trabalho (OLIVEIRA et al., 2004). De forma complementar, Morin, Tonelli e Pliopas (2007) explicam que um trabalho pode ser considerado sem sentido se aquele que o executa não contribui para a sua criação e concepção. Morin (2001), ao explorar a questão da clareza dos objetivos do trabalho, amplia a discussão, incluindo aspectos relacionados à organização da tarefa e do trabalho como um todo. Segundo a autora, para que o trabalho seja percebido como dotado de sentido, “é importante que a organização das tarefas e das atividades torne-se favorável à eficiência e que os objetivos visados, assim como os resultados esperados, sejam claros e significativos para as pessoas que o realizam.” (MORIN, 2001, p. 16). Assim, não apenas o trabalho precisa ter um objetivo claro para quem o realiza, mas sua organização precisa ser percebida pelo trabalhador como eficiente, pois práticas de gestão incompreensíveis e/ou ambíguas contribuem para que o trabalho perca o seu sentido.

Um trabalho desestruturado, cuja finalidade é de difícil compreensão por parte daquele que o realiza, pode ser percebido como improdutivo, que não gera resultados efetivos para a empresa. Um trabalho cuja utilidade não pode ser constatada perde o sen- 
tido de sua realização (OLIVEIRA et al., 2004; MORIN; TONELLI; PLIOPAS, 2007; ROSSO; DEKAS; WRZESNIEWSKI, 2010). Dessa maneira, o trabalho tem sentido se o seu resultado puder ser utilizado para algum propósito que agregue valor à empresa. Trabalhos executados de forma automática, sem que seus resultados sejam efetivamente aplicados, têm sua utilidade e, consequentemente, seu sentido comprometidos.

Para ser provido de sentido, o trabalho deve ter utilidade não apenas para a organização, mas também para outros indivíduos. England e Whiteley (1990 apud MORIN, 2001), ao estratificarem a definição de trabalho em seis padrões distintos, identificaram que em um padrão específico o trabalho foi definido como "uma atividade que beneficia os outros, que traz uma contribuição para a sociedade [...]” (MORIN, 2001, p. 13). De forma complementar, o Meaning of Working International Research Team (MOW, 1987), que realizou uma das mais completas pesquisas sobre o sentido do trabalho, debate a questão do trabalho sob três principais eixos, entre os quais as normas sociais do trabalho, que contemplam os direitos e deveres dos trabalhadores. Sob essa ótica, os trabalhadores teriam o "dever de contribuir para o bem social pelo seu trabalho” (TOLFO; PICCININI, 2007, p. 39). A utilidade, seja para a organização, para outros indivíduos, seja para a sociedade, é apontada na literatura como uma das principais fontes de sentido atribuído ao trabalho (MOW, 1987; MORIN, TONELLI; PLIOPAS, 2007; ROSSO; DEKAS; WRZESNIEWSKI, 2010).

A pesquisa sobre o sentido do trabalho, quando se concentra em uma parcela específica de indivíduos, contempla majoritariamente grupos específicos de trabalhadores, como servidores públicos ou professores universitários. Dessa forma, ainda são tímidos os trabalhos que abordam a questão geracional, com destaque para Cavazotte, Lemos e Viana (2012) e Teixeira et al. (2014). Nesses últimos, os achados indicam que os jovens da Geração Y atribuem sentido a um trabalho "que seja feito em um ambiente seguro e sadio [...] que reconheça minhas competências [e que] me permite aprender e me aperfeiçoar [...] eu tenha prazer em fazer.” (TEIXEIRA et al., 2014, p. 33). A segurança do ambiente também já foi apontada por Cavazotte, Lemos e Viana (2012) como questão relevante para o sentido do trabalho aos que pertencem à Geração Y.

\section{ASPECTOS METOdOLÓGICOS}

Optou-se, neste trabalho, por uma metodologia de pesquisa qualitativa, o que possibilitou aos entrevistadores compreenderem os aspectos subjetivos associados às escolhas profissionais dos entrevistados. Assim, foram realizadas entrevistas em profundidade, com 12 jovens, com o objetivo de elucidar os motivos que os levaram a 
deixar as grandes corporações em que trabalhavam. Para que fossem considerados aptos a participar da pesquisa, os jovens deveriam ter nascido a partir de 1980 (inclusive), possuir experiência prévia no mundo corporativo privado e já ter efetivamente abandonado seu emprego nessas empresas em busca de outros caminhos profissionais.

A captação desses jovens ocorreu a partir da técnica denominada "bola de neve”, em que os próprios entrevistados indicam outras pessoas com o perfil que se busca pesquisar. Os quatro primeiros entrevistados eram conhecidos dos pesquisadores, e os demais foram indicações destes ou dos demais entrevistados. As entrevistas tiveram duração média de 30 minutos e foram realizadas entre janeiro e março de 2015.

As entrevistas foram baseadas em um roteiro composto por indagações sobre as experiências anteriores desses indivíduos no setor privado; sobre os motivos que os levaram a deixar essas empresas; sobre o trabalho atual e as razões dessa escolha; sobre os pontos considerados positivos nas empresas nas quais trabalharam; bem como sobre as expectativas futuras relativas ao trabalho atual. No decorrer das entrevistas foram feitas perguntas complementares, com vistas a aprofundar aspectos considerados obscuros nas falas dos entrevistados, mas com o cuidado de não direcionar as respostas. Os relatos foram gravados e transcritos na íntegra para permitir sua posterior análise.

Ao analisarem as transcrições das entrevistas, os pesquisadores buscaram identificar os principais aspectos que justificaram a saída dos jovens de grandes empresas e sua opção por outros rumos profissionais. Para isso, foi utilizada a análise de conteúdo (BARDIN, 2009). Após a leitura das transcrições, os pesquisadores codificaram as unidades de registro de acordo com os temas que foram posteriormente classificados conforme os critérios léxicos e semânticos (BARDIN, 2009). Nesse ponto foram identificadas diversas referências ao sentido do trabalho como fator de insatisfação dos entrevistados, exigindo dos pesquisadores a revisão da literatura sobre essa temática acrescentada na seção do referencial teórico. Ao final do processo de codificação, o sentido do trabalho foi classificado como uma categoria separada.

\section{APRESENTAÇÃO E DISCUSSÃO DOS RESULTADOS}

Conforme anteriormente destacado, a análise das entrevistas teve como objetivo identificar os principais motivos que vêm levando jovens a migrarem de seus empregos em grandes empresas privadas para outros caminhos profissionais, como se tornarem empresários, funcionários públicos ou professores/pesquisadores. As diversas trajetórias seguidas por esses profissionais sugerem motivações e realizações dis- 
tintas e, por isso, nesta pesquisa visou-se o contato com profissionais que optaram por diferentes carreiras. O resumo do perfil dos entrevistados está exposto no Quadro 1.

Quadro 1 - Perfil dos entrevistados

\begin{tabular}{|l|l|l|l|}
\hline \multicolumn{1}{|c|}{ Entrevistado } & \multicolumn{1}{c|}{ Gênero } & \multicolumn{1}{c|}{ Ocupação } \\
\hline E1 & Masculino & 33 & Professor \\
\hline E2 & Feminino & 30 & Empresária \\
\hline E3 & Feminino & 31 & Professora \\
\hline E4 & Feminino & 29 & Professora \\
\hline E5 & Masculino & 28 & Empresário \\
\hline E6 & Masculino & 34 & Professor \\
\hline E7 & Feminino & 29 & Empresária \\
\hline E8 & Feminino & 32 & Empresária \\
\hline E9 & Masculino & 30 & Funcionário público \\
\hline E10 & Feminino & 30 & Funcionária pública \\
\hline E11 & Feminino & 29 & Funcionária pública \\
\hline E12 & Masculino & 30 & Empresário \\
\hline Fonte: 0s autores. & & &
\end{tabular}

Fonte: os autores.

Tendo como referência a literatura que retrata as expectativas profissionais e pessoais da Geração Y, observou-se que a maioria dos aspectos apontados pelos jovens como fontes de sua insatisfação encontra eco nas descrições presentes nessa literatura. Os entrevistados alegam ter deixado seus empregos nas grandes empresas por terem encontrado pouca autonomia decisória, pouca flexibilidade, além de se ressentirem quanto à insatisfação no exercício de suas atividades e ao comprometimento de sua qualidade de vida, em grande medida decorrente do excesso de trabalho. Mas esses aspectos, apesar de alinhados com a literatura sobre os "Yrs", não foram os únicos destacados pelos entrevistados. $\mathrm{O}$ anseio por segurança também motivou alguns respondentes a migrarem para o setor público, o que contraria a caracterização desses indivíduos como propensos a correr riscos. Todavia, o aspecto que mais chamou a atenção dos pesquisadores nos relatos foi a frequente referência à falta de sentido no trabalho anteriormente executado. A busca por um "sentido” no que se faz e a rejeição à falta deste, nas situações profissionais vividas, estiveram presentes nas falas da maioria dos entrevistados, de forma direta ou indireta, o que motivou a explorar com mais profundidade esse aspecto, pouco discutido na literatura que aborda os anseios dos jovens.

Para discutir o conteúdo das entrevistas, dividiu-se esta seção em seis subseções as quais analisam os principais fatores de rejeição desses jovens às suas antigas organizações. As quatro primeiras subseções discutem os aspectos mencionados pelos 
entrevistados que encontram ressonância na literatura corrente sobre a Geração Y. A quinta aborda a busca por segurança, e a sexta explora a questão do sentido do trabalho.

\subsection{REJEIÇÃO A UM TRABALHO SEM AUTONOMIA}

A palavra autonomia esteve presente nas falas da maioria dos entrevistados, logo, a julgar pelos relatos obtidos, esses jovens anseiam por mais liberdade decisória e menos direcionamento em suas atividades. As críticas feitas pelos entrevistados às situações de trabalho anteriores ora se referem à incoerência no discurso das empresas que cobram criatividade, mas cerceiam a liberdade de seus funcionários: "hoje se fala muito de inovação, de pessoas inovadoras, sejam criativas, autônomas, e ao mesmo tempo você não dá autonomia para elas, você fala como elas devem fazer” (E4), ora revelam a frustração no exercício de funções gerenciais com grandes limitações decisórias: “eu acho que estar em um ambiente que você já chega a ter um certo poder de decisão e você vê que você não consegue mudar umas coisas é muito frustrante.” (E7) (informações verbais).

A valorização da autonomia nos relatos dos entrevistados vai ao encontro da literatura que caracteriza a Geração Y como afeita à maior liberdade do que seus antecessores (ALSOP, 2008; CENNAMO; GARDNER, 2008). Nesse sentido, o cerceamento a essa liberdade parece ter sido um aspecto que motivou esses jovens a buscarem novos rumos profissionais: "isso no passar do tempo foi me deixando desmotivada. Além disso, a falta de autonomia, porque já estava tudo pronto, porque a empresa é grande e mais antiga.” (E8) (informação verbal).

Ao descreverem seu novo trabalho, alguns entrevistados destacam, justamente, a liberdade encontrada, seja em relação à tarefa: “[...] a maioria dos projetos a gente que busca, então tem liberdade de escrever projetos editais, procurar artistas, de ir atrás do que quer. Projetos que a gente tem orgulho de trabalhar.” (E2), seja em relação à gestão e organização do seu próprio tempo: “Eu consigo responder pelos meus atos. Organizar o meu tempo, adequar o meu trabalho à minha necessidade de vida e organizar a minha vida em relação ao trabalho.” (E12) (informações verbais).

Finalmente, a ânsia por liberdade e autonomia aparece, também, quando os entrevistados falam de seus planos futuros:

Estar inserido em uma grande instituição de ensino, dando aula e fazendo pesquisa, de preferência com uma autonomia que eu consiga fazer pesquisas dentro de assuntos que me interessam, 
dentro de coisas que têm uma relevância para mim e para a sociedade. (E6) (informação verbal).

\title{
4.2 REJEIÇÃO A UM TRABALHO SEM QUALIDADE DE VIDA
}

Assim como o tema anterior, a melhoria da qualidade de vida também foi frequentemente mencionada pelos entrevistados como um aspecto que os motivou a buscarem novas oportunidades de trabalho. Essa questão também está alinhada à literatura (ALSOP, 2008; ERICKSON, 2008) que enfatiza o desejo desses jovens conciliarem suas vidas pessoal e profissional, de forma a manterem sua qualidade de vida. Essa qualidade tanto é reflexo de horários menos rígidos: “[...] para mim qualidade de vida é em primeiro lugar. Eu gosto de acordar bem, não quero acordar madrugando, trabalhando de madrugada" (E5), quanto da maior flexibilidade de horário e jornada de trabalho: "Ganho bem, tenho uma carga horária de trabalho flexível e eu vejo que a qualidade de vida que eu tenho hoje como promotor de justiça é muito melhor do que a qualidade de vida que eu teria trabalhando hoje no setor privado.” (E9) (informações verbais).

$\mathrm{O}$ contraste entre as atuais condições de trabalho e as anteriores, vivenciadas nas grandes empresas, foi frequente e motivo de rejeição à dinâmica de trabalho naquelas organizações:

\begin{abstract}
Não quero voltar para empresa grande nesse momento, estou muito feliz. Está fazendo muito sentido, eu estou conseguindo equilibrar melhor a minha vida, a minha qualidade de vida. Estou fazendo a pós-graduação, estou conseguindo ir. (E8).
\end{abstract}

Não é igual a uma multinacional, mas eu tenho a oportunidade única, de estar em uma estrutura familiar muito legal, próxima à minha residência, então hoje em dia o que eu tive ganho de qualidade de vida, estou no trabalho em 10 minutos. E isso é uma coisa que conta muito. (E12) (informação verbal).

Assim, mais do que valorizar apenas a remuneração e os desafios que as empresas podem lhes oferecer, esses indivíduos também querem destinar seu tempo às atividades que lhes dão prazer fora do ambiente de trabalho. Uma vez que as organizações em que estavam empregados não lhes possibilitavam essa conciliação, tais profissionais buscaram outras alternativas de trabalho. O relato seguinte ilustra a satisfação de um dos entrevistados em trabalhar em condições que lhe proporcionam melhor qualidade de vida: 
E eu tinha uma qualidade de vida fora da realidade (como pesquisador) porque eu ia para a universidade a hora que eu acordava, não tinha preocupação com horário, saia de lá a hora que eu achava que meu trabalho tinha sido bem desenvolvido aquele dia, então eventualmente eu voltava às 16 horas, às vezes às 11 da noite. Se alguém me chamasse para jogar um futebol no final da noite eu ia, se me chamassem para um churrasco sexta à tarde eu poderia estar lá e isso para mim é uma coisa que não dá para precificar. (E1) (informação verbal).

A busca por um trabalho que permita que se tenha melhor qualidade de vida também já havia sido observada em vários outros estudos que descrevem essa Geração (SÁ; LEMOS; CAVAZOTTE, 2014; ERICKSON, 2008; ALSOP, 2008).

\subsection{REJEIÇÃO A UM TRABALHO SEM FLEXIBILIDADE}

A insatisfação em razão da falta de flexibilidade, tanto no que diz respeito aos horários quanto ao local de trabalho também motivou os entrevistados a buscarem alternativas profissionais. Assim como exposto nos tópicos anteriores, esse é mais um aspecto que encontra ressonância na literatura sobre os "Yrs". Caracterizados como dinâmicos e sempre em busca de novos desafios na sua vida profissional, os "Yrs" não gostam de trabalhar em organizações que possuam estruturas rígidas e inflexíveis (ALSOP, 2008; CENNAMO; GARDNER, 2008). O horário rígido exigido por algumas empresas foi considerado um "elemento que me fez desacreditar, não gostar, não ser o meu perfil de trabalho. Um horário muito inflexível” (E9) (informação verbal), especialmente porque, segundo os entrevistados, o cumprimento de horários fixos gerava incoerências, pois “o período que tinha pouco trabalho eu tinha que estar lá de manhã, sem ter o que fazer, e não tinha nenhuma flexibilidade.” (E1) (informação verbal).

A análise das entrevistas permitiu observar que a rigidez de horários levou alguns entrevistados a deixarem suas antigas organizações em busca de novas oportunidades que lhes oferecessem maior flexibilidade:

Eu tomei a decisão de vir para uma estrutura familiar menor, também pensando nisso. Eu consigo ter um poder de decisão melhor, autonomia no meu trabalho, fazer o meu horário, organizar meu dia, posso vir não trabalhar em um dia, sem dar satisfação a ninguém. (E12) (informação verbal). 
Não apenas o horário, mas a flexibilidade é requerida também em relação ao local de trabalho. O estrevistado 5 explica que “[...] eu não consigo ter horário, não tem jeito. Às vezes eu fico sozinho fazendo o meu trabalho, às vezes eu quero trabalhar sozinho no Starbucks.” (informação verbal).

Pode-se, inclusive, considerar esse aspecto complementar aos anteriormente abordados, autonomia e qualidade de vida, pois a flexibilidade tanto permite ao trabalhador maior autonomia quanto ao exercício de suas atividades, na medida em que este escolhe hora e local para executá-las, quanto lhe assegura melhor qualidade de vida, por esse mesmo motivo. Esse aspecto já havia sido abordado por Sá, Lemos e Cavazotte (2014) em pesquisa acerca das expectativas de carreira de jovens profissionais. Neste estudo também foi possível identificar a conexão dos conceitos qualidade de vida e flexibilidade nas organizações. Conforme destacaram as autoras, para os integrantes da Geração Y, ter horário e local de trabalho flexíveis, em que se pode escolher com maior liberdade o momento de desempenhar suas funções, é um recurso que lhes assegura uma vida no trabalho com maior qualidade.

O entrevistado 5, que abriu a sua empresa há poucos anos, sintetiza a associação entre os dois conceitos quando afirma que na sua empresa "[...] todo mundo tem horário flexível, eu quero que todo mundo tenha qualidade de vida boa.” (informação verbal). Dessa forma, é possível afirmar que esses jovens valorizam essa flexibilidade ao ponto em que, quando passam a ser os dirigentes de suas empresas, procuram proporcionar aos seus empregados opções que lhes foram negadas nas grandes empresas. Há, assim, uma rejeição aos ambientes de trabalho que não lhes permite trabalhar da forma que julgam mais produtiva.

\subsection{REJEIÇÃO A UM TRABALHO DESPRAZEROSO}

Os relatos obtidos indicam que a falta de prazer ao executar suas atividades afastou os jovens profissionais de antigos trabalhos. Esses depoimentos também encontram ressonância na literatura que caracteriza a Geração Y como hedonista, buscando o prazer e a satisfação pessoal naquilo que desempenha (ALSOP, 2008; SMOLA; SUTTON, 2002). Por esse motivo, tais indivíduos procuram ambientes de trabalho que lhes propiciem desafios e realizações, pois acreditam que "a expectativa [...] é trabalhar bem, com as coisas que eu gosto, fazendo o que eu gosto.” (E2). Segundo a entrevistada 7, "incomodava fazer o que eu não acreditava, eu achava sacal.” (E7) (informações verbais). 
Para os entrevistados fazerem um trabalho sem prazer isso significava frustração: “Tive algumas decepções em algumas dessas empresas pelo que eu fazia, eu achava que poderia fazer coisas melhores, e fazia coisas muito burocráticas.” (E1) (informação verbal).

Esse prazer no trabalho é potencializado a partir do momento em que tais jovens são reconhecidos pelas atividades que desempenham, por isso, esses indivíduos rejeitam as organizações que não valorizam seu trabalho (CAVAZOTTE; LEMOS; VIANA, 2012). De acordo com a literatura, esses indivíduos sempre foram elogiados durante a sua criação, logo dependem de estímulos subjetivos para continuarem motivados a desempenhar as suas funções com excelência (ALSOP, 2008; LIPKIN; PERRYMORE, 2010). Assim, não apenas a realização e o prazer oriundos do trabalho, mas também o reconhecimento deste é valorizado pelos entrevistados: "Mas eu não gostava de algumas coisas, por exemplo, às vezes você fazia um negócio genial ou vendia uma parada irada, e ai eles viravam e falam só parabéns. Eu sentia falta de uma coisa que fosse mais realizadora pra mim.” (E5) (informação verbal).

Por vezes, a realização com o trabalho recebe contornos mais subjetivos em detrimento de aspectos econômicos: “A questão não é só a remuneração, isso não importa muito em certo momento. A questão é o quanto eu consigo agregar de valor com o meu trabalho, o quanto eu consigo agregar de conhecimento.” (E12) (informação verbal).

Assim, é possível observar que esses jovens buscam trabalhos que lhes deem prazer e senso de realização, seja em razão das tarefas que lhes são designadas, seja em razão do reconhecimento pelo seu desempenho. Cabe destacar, todavia, que a busca por prazer no trabalho reflete mais os anseios dos jovens que saíram de grandes empresas privadas para empreender ou ingressar no mundo acadêmico, pois aqueles que se tornaram funcionários públicos estão mais em busca de estabilidade profissional, valorizando menos o escopo do trabalho.

\subsection{REJEIÇÃO A UM TRABALHO SEM SEGURANÇA}

Apesar de boa parte da literatura que os caracteriza descrever os jovens profissionais como pessoas afeitas ao risco e sempre em busca de novos desafios (VASCONCELOS et al., 2010; LIPKIN; PERRYMORE, 2010), os relatos obtidos nem sempre confirmaram essa caracterização. Conforme dito anteriormente, alguns dos entrevistados optaram por construir suas carreiras em organizações públicas. Segundo os relatos, essa opção acontece por “uma questão de estabilidade no futuro (E7)” (informação ver- 
bal), uma vez que esse tipo de empresa oferece maior segurança diante da imprevisibilidade do mercado de trabalho. Dessa forma, as empresas públicas são procuradas pelos entrevistados como forma de proteção contra demissões. O entrevistado 9 explica tal situação ao justificar sua opção por fazer o concurso público: "Primeiramente, [eu fiz concurso público] pela estabilidade financeira e de ter a certeza que dificilmente você vai ser mandado embora. Você sabe que nunca vai ser rico ou milionário, mas que no final do mês você vai ter o seu salário lá certo.” (informação verbal).

A longevidade oriunda da estabilidade também foi destacada pela entrevistada 10 ao afirmar que na decisão de fazer o concurso público "estabilidade era fundamental” e que "quando eu tomei posse eu pensei: eu vou me aposentar aqui." (informação verbal). Cabe destacar, todavia, que a busca por estabilidade, apesar de contrariar a maioria das descrições encontradas na literatura internacional sobre essa geração, também já havia sido identificada na pesquisa realizada por Cavazotte, Lemos e Viana (2012). Assim como no estudo das referidas autoras, a presente pesquisa também identificou, como uma das razões para essa valorização, o fato de alguns desses jovens terem visto seus pais passarem por dificuldades financeiras associadas a situações de trabalho incertas, não querendo viver essa realidade. Como relata o entrevistado 11, "O que me motivou a isso foi o meu pai, que trabalha na área de informática, e em um certo momento ele teve complicações financeiras.” (E11) (informação verbal).

Logo, apesar de a literatura apresentar os integrantes da Geração Y como propensos a mudar de emprego quando insatisfeitos, percebe-se que não se pode generalizar essa afirmação, posto que há, entre os "Yrs”, aqueles que prezam a segurança, estando inclusive dispostos a abrir mão de outros valores em nome desta.

\subsection{REJEIÇÃO A UM TRABALHO SEM SENTIDO}

Conforme anteriormente mencionado, além dos temas já discutidos nesta análise, uma questão chamou particularmente a atenção dos pesquisadores durante as entrevistas: a frequente menção ao "sentido do trabalho". À exceção dos entrevistados 5 e 12, todos os demais mencionam, diretamente ou indiretamente, essa questão. $\mathrm{O}$ fato de esse tema não aparecer na literatura que aborda as aspirações dos jovens contemporâneos - o aspecto que talvez se aproxime desse tema seja a questão do prazer no trabalho, todavia sem retratar a complexidade subjacente ao sentido - motivou a criação desta última categoria analítica.

Por esse motivo, nesta seção foram agrupadas as falas dos entrevistados que fizeram alguma menção à falta de sentido do trabalho como uma fonte de insatisfação 
que os motivou a migrarem para outra empresa ou carreira. Essa categoria sugere que a empresa privada tradicional se mostrou incapaz de oferecer um trabalho provido de sentido para os jovens entrevistados. Por motivos diversos, a seguir detalhados, pode-se especular que a impossibilidade de atribuir sentido ao trabalho executado fez com que esses jovens se afastassem do emprego em busca de outras formas de trabalho nas quais pudessem encontrar um sentido.

Em seus relatos, alguns entrevistados declaram, de forma explícita, que não viam mais sentido naquele trabalho que faziam. Ao ser perguntada sobre qual razão a levou a sair do emprego em uma empresa privada tradicional, a entrevistada 3 explica que “a principal é a questão do sentido mesmo, d'eu não ver sentido naquilo que eu estava fazendo. Aquilo de alguma forma não completava.” (informação verbal). Essa falta de sentido pode ser atribuída à percepção do trabalho como algo associado apenas à sobrevivência, o que foi considerado insuficiente para um dos entrevistados, não obstante a literatura que discute o tema destacar que prover a subsistência é um dos sentidos do trabalho: “Aquilo ali para mim não tinha mais o menor sentido, você dedicar uma vida só para você se manter, viver na mediocridade. O ápice da sua vida são 30 dias de férias.” (E6) (informação verbal).

O trabalho também perde o sentido para os entrevistados quando se torna um trabalho alienado, em que o executante não mais domina sua concepção e/ou desconhece seu propósito. O trabalho alienado emerge nos depoimentos dos entrevistados ao descreverem que realizavam tarefas rotineiras e enfadonhas, sem saberem ao certo qual era o seu objetivo. A entrevistada 8 cita a falta de um objetivo mais explícito em suas atividades como algo capaz de fazer com que o trabalho perca o sentido:

No meu último emprego eu ganhava bem mas eu não via sentido naquilo que eu estava fazendo. Isso me incomodava muito. Às vezes eu chegava no trabalho e falavam que eu tinha que fazer tal reunião, mas eu não sabia qual era o motivo. Falavam para eu ir para ficar lá e ouvir, porque era importante que o RH estivesse presente, mesmo eu não tendo menor condição de opinar em nada. (informação verbal).

Tais depoimentos vão ao encontro do exposto na literatura (OLIVEIRA et al., 2004; MORIN; TONELLI; PLIOPAS, 2007) ao se afirmar que, para atribuir sentido ao trabalho que realiza, o trabalhador precisa ter conhecimento do propósito do trabalho bem como contribuir para a sua criação e concepção. Pode-se complementar que essa questão se desdobra para a dimensão organizacional, uma vez que esse trabalho é 
percebido pelos entrevistados como improdutivo e, por isso, inútil para a organização. Corroborando essa argumentação, a entrevistada 3 afirma que seu trabalho se resumia a:

[...] rodar planilhas que não diziam nada para mim, era aquela rotina, roda planilhas, aí tem a reunião que não serve para nada, não se resolve nada em reuniões, então eu fazia o meu dia muito ruim, não via sentido para mim no sentido de que, para que que eu estou fazendo isso? [...] (informação verbal).

Para alguns entrevistados o trabalho também traz questionamentos mais complexos a respeito da própria vida e do lugar que o trabalho, nela, ocupa. A rotina gerada pelo trabalho faz com que as pessoas se questionem sobre sua existência e o sentido que o trabalho possui:

Quando eu me formei, eu já trabalhava, e eu falei assim que mudou na minha vida, nada. Eu tinha 25 anos e eu pensei: eu vou ter que fazer isso por mais 25, 40 anos? É isso? Minha vida vai se resumir a isso? Saí de casa trabalhar, ir fazer orçamento e voltar? Isso para mim foi extremamente problemático. Eu fiquei pensando o que eu estava fazendo da minha vida. (E6) (informação verbal).

Além dessas questões, os entrevistados também relataram que o sentido de seu trabalho provém da utilidade que este pode ter para outra pessoa. Dessa forma, os entrevistados buscam uma forma de transformar a vida de outras pessoas por meio da realização do seu trabalho, conseguindo, dessa maneira, atribuir sentido a ele. Contudo, nos depoimentos, foi possível perceber que essa forma de dar sentido ao seu trabalho não foi alcançada na empresa privada tradicional. Questionada sobre suas motivações ao adentrar o mercado corporativo privado, a entrevistada 4 relatou que pretendia "desenvolver pessoas para atingir um resultado. Atingir pessoas para atingir o objetivo da organização.” (informação verbal). Porém, por não conseguir atingir esse objetivo na empresa em que trabalhava, voltou sua carreira para o setor acadêmico, acreditando que:

A docência te possibilita atingir o maior número de pessoas que estão em formação e que querem aprender, e que estão ali. [pois] Com vinte alunos em sala você fazer com que cinco refletirem sofre essas questões eu acho que eu vou estar contribuindo muito mais. (E4) (informação verbal). 
De forma similar, a entrevistada 8, também formada em Psicologia e atuante na área de recursos humanos, explica que, por meio do seu trabalho nessa área, pretendia que as pessoas percebessem “o sentido do trabalho para ela [pois] na verdade, a faculdade me ensinou que o trabalho é significativo no desenvolvimento humano.” (informação verbal).

O desejo de impactar a vida de outras pessoas surgiu também em um espectro mais amplo, em que o trabalho adquire sentido quando é útil e contribui para toda a sociedade (MOW, 1987; MORIN, 2001; TOLFO; PICCININI, 2007). Desse modo, os entrevistados que compartilham da vontade de "construir um mundo melhor, [...] investir na sociedade, no coletivo” (E6) não conseguem atribuir sentido ao trabalho no interior das empresas privadas tradicionais, uma vez que acreditam que a empresa “não pensa no todo, não tem o menor senso coletivo, é extremamente capitalista, pensa no acionista e pronto [...]” (E6) (informação verbal). Assim, o trabalho no interior da empresa privada tradicional perde o sentido por não oferecer a oportunidade de o indivíduo contribuir de forma substancial para a sociedade:

Eu acho que eu percebi que eu poderia contribuir mais para a sociedade de uma maneira diferente, porque quando eu decidi trabalhar na empresa eu queria atingir mais pessoas com o meu trabalho e eu passei a ver que eu não estava cumprindo o meu objetivo de vida. (E4) (informação verbal).

O trabalho desprovido de sentido foi apontado pelos entrevistados como uma causa importante do abandono de seu emprego em empresas privadas tradicionais. A falta de sentido no trabalho apareceu associada à natureza das atividades realizadas, às contradições identificadas na gestão da empresa na qual atuavam, bem como à percepção da falta de utilidade desse trabalho para outras pessoas e, em última instância, para a sociedade como um todo.

\section{CONSIDERAÇÕES FINAIS}

O objetivo com a presente pesquisa foi compreender os motivos que vêm levando jovens a abandonarem seus empregos nas empresas privadas tradicionais. Como objeto de pesquisa, foram estudados indivíduos que fizeram essa escolha e iniciaram uma nova carreira nos setores público ou acadêmico ou que resolveram empreender. Os achados do estudo indicam que, apesar de alguns aspectos apontados pelos jovens como razão de seu descontentamento encontrarem ressonância na literatura sobre a Geração Y, os entrevistados relataram outros tipos de insatisfações com 
o trabalho na empresa privada tradicional ainda pouco explorados em estudos anteriores. Coincidente com a literatura, os jovens relataram que efetivaram a troca em busca de autonomia, qualidade de vida, flexibilidade e prazer no trabalho. Contudo, essas características não se apresentaram de forma homogênea entre eles. A rejeição ao trabalho desprazeroso mostrou-se mais presente na fala dos jovens que optaram por criar seu próprio negócio. Pode-se supor que a busca por um trabalho que lhes propicie mais prazer serve de motivação para que esses jovens abandonem seus empregos para abrir suas próprias empresas.

No que diz respeito à busca por autonomia, esta mostrou-se menos presente nas aspirações dos profissionais do serviço público. Essa informação indica que há, entre os entrevistados, diferentes perfis, e a escolha da nova carreira varia em decorrência dessas diferenças. Assim, os profissionais que optaram por trabalhar em empresas públicas, com estruturas rígidas e muitos níveis hierárquicos, não almejam, primordialmente, maior autonomia, mas buscam segurança. Por isso, apesar de frequentemente mencionada na literatura sobre jovens, a busca por autonomia não é uma aspiração comum a toda uma geração. De forma análoga, a busca por flexibilidade também não se mostrou como preocupação dos profissionais do serviço público. Possivelmente, ao fazer um concurso para ingressar em uma empresa pública, o profissional está a par das restrições de horários e local de trabalho às quais será submetido, e esse fato não parece ser um problema para ele.

Conforme mencionado, os profissionais que buscaram as empresas públicas como alternativa ao trabalho em empresas privadas tradicionais demonstraram rejeição ao trabalho sem estabilidade. A valorização da estabilidade contradiz parte da literatura que caracteriza o jovem dessa geração como um profissional instável, afeito a risco e em constante busca por mudanças. Essa contradição, todavia, já havia sido apontada por Cavazotte, Lemos e Viana (2012), que identificaram expectativas “conservadoras” entre os jovens profissionais pesquisados. Cabe destacar, porém, que a literatura sobre os "Yrs" tem, predominantemente, estudado aquilo que os jovens aspiram, refletindo desejos que podem se mostrar diferentes daquilo que realmente é feito quando esses indivíduos decidem abandonar a carreira tradicional. Pode-se postular, portanto, que quando perguntados sobre seus anseios, os jovens demonstram um perfil arrojado e com inclinação para a mudança. Contudo, ao efetivar a troca de carreira, tema da presente pesquisa, é possível que parte desses jovens procurem alternativas mais conservadoras. A busca por um trabalho estável reflete o anseio por segurança, deixando o profissional menos vulnerável às oscilações do mercado de trabalho. Com base nisso, pode-se problematizar o desejo por segurança associado com 
autonomia e flexibilidade. Seria impreciso, portanto, afirmar que os jovens que estão construindo sua carreira no setor público não desejam autonomia e flexibilidade, mas os dados sugerem que esse profissional preza mais por sua segurança em detrimento desses outros atributos.

Mas se acredita que o achado mais relevante da pesquisa foi identificar a insatisfação manifestada pelos jovens diante de um trabalho considerado sem sentido. Esse tema, pouco presente nas caracterizações da dita Geração Y, emergiu como demanda recorrente entre os entrevistados. Assim, pode-se especular que esses indivíduos consideravam que o trabalho realizado nas empresas privadas tradicionais era desprovido de sentido e não contribuía para a sociedade. Essa preocupação indica que as empresas privadas parecem estar sendo falhas em gerar trabalhos providos de sentido, para parte de seus jovens integrantes. Todavia, cabe destacar que apesar de citado por quase todos, o trabalho sem sentido como razão da insatisfação no emprego anterior foi um tema mais presente no discurso dos profissionais que fizeram a transição para o setor acadêmico. Alguns pontos podem explicar essa predominância como uma crítica mais apurada do ambiente corporativo, baseada na literatura encontrada nos cursos de mestrado e doutorado ou a mudança mais radical de carreira, pois esses profissionais pertencem ao grupo que não se manteve trabalhando em empresas e, por isso, podem ter tido contato com outra realidade de práticas organizacionais. Esses profissionais procuram, por meio de seu trabalho, ser, de alguma forma, úteis para a sociedade.

A partir do analisado nesta pesquisa, alinhado com Lemos (2012) e Oliveira, Piccinini e Bitencourt (2012), também se acredita ser questionável o tratamento homogêneo dado aos diversos profissionais que compõem a denominada Geração Y. Ao se fazer isso, coloca-se sob a mesma alcunha diferentes perfis de indivíduos que não necessariamente apresentam os mesmos padrões de comportamento.

De forma conclusiva, cabe destacar que nesta pesquisa foram apresentados seis aspectos que fazem com que os jovens rejeitem as carreiras nas empresas tradicionais: falta de autonomia; dificuldade em conciliar vida pessoal e profissional; pouca flexibilidade de local e horário de trabalho; falta de prazer no trabalho; falta de segurança; e falta de sentido no trabalho executado. Apesar de se perceber uma variação da ênfase de cada um em relação aos perfis dos profissionais pesquisados, a carência dessas características no trabalho ofertado pelas empresas privadas tradicionais sugere um possível desgaste do modelo de trabalho e carreira oferecido por essas empresas. Curiosamente, muitas delas estão envolvidas em processos que buscam aumentar a motivação e o comprometimento de sua força de trabalho, com vistas a 
melhorar seus indicadores de rotatividade de pessoal. Esse fato sugere um possível descompasso entre esses processos e as aspirações de parte dos profissionais que formam o mercado de trabalho atual. Nesse sentido, com o presente trabalho pode-se contribuir para que essas empresas repensem suas estratégias voltadas para a atração e retenção da jovem força de trabalho.

Os achados da presente pesquisa também ensejam novos temas a serem aprofundados em estudos futuros. O primeiro diz respeito ao entendimento mais matizado dos diferentes perfis e das diferentes expectativas profissionais dos jovens contemporâneos, comumente retratados na literatura como um grupo quase homogêneo. Outro aspecto a ser explorado se refere ao tema sentido do trabalho, saliente nos relatos obtidos, mas que ainda requer um melhor entendimento acerca dos significados atribuídos a esse conceito, pelos jovens profissionais. Em outras palavras, quando esses indivíduos afirmam que desejam realizar um "trabalho com sentido", do que falam, exatamente ? Estudos futuros podem ajudar a responder a essa pergunta. Finalmente, pesquisas futuras dedicadas a discutirem políticas e práticas de gestão de recursos humanos nas organizações contemporâneas podem explorar, em especial, as expectativas dos novos entrantes referentes a elas.

\section{REFERÊNCIAS}

ALSOP, R. The trophy kids grow up: how the millennial generation is shaking up the workplace. São Francisco: Jossey-Bass, 2008.

ANDRADE, S. P. C.; DA ROSA, S. T.; DELLAGNELO, E. H. L. Sentidos do Trabalho e Racionalidades Instrumental e Substantiva: Interfaces entre a Administração e a Psicologia. Revista de Administração Contemporânea, v. 16, n. 2, p. 200, 2012.

BARDIN, L. Análise de conteúdo. Lisboa: Edições 70, 2009.

BEYDA, T. T.; CASADO, R. U. Relações de trabalho no mundo corporativo: possível antecedente do empreendedorismo? Cadernos EBAPE. BR, v. 9, n. 4, p. 10661084, 2011.

CAVAZOTTE, F. de S. C. N.; LEMOS, A. H. da C.; VIANA, M. D. de A. Novas gerações no mercado de trabalho: expectativas renovadas ou antigos ideais? Cadernos EBAPE.BR, v. 10, n. 1, p. 162-180, mar. 2012. 
CENNAMO, L.; GARDNER, D. Generational differences in work values, outcomes and person-organization values fit. Journal of Managerial Psychology, v. 23, i. 8, p. 891-906, 2008.

CORSEUIL, C. H. et al. A rotatividade dos jovens no mercado formal brasileiro. Mercado de Trabalho: conjuntura e análise, Brasília, DF, v. 18, n. 55, p. 23-29, 2013.

CÔRTES, L. L.; SILVA, J. R. G. Construção do contrato psicológico de indivíduos que ingressam em organizações do setor público no atual contexto brasileiro: estudo de caso em uma empresa estatal. In: ENANPAD, 30., 2006, Salvador. Anais... Salvador, 2006.

DEPARTAMENTO INTERSINDICAL DE ESTATÍSTICA E ESTUDOS SOCIOECONÔMICOS. Os números da rotatividade no Brasil: Um olhar sobre dados da Rais 2002-2013. 2014. Disponível em: <www.dieese.org.br/notaaimprensa/2014/numerosRotatividadeBrasil.pdf>. Acesso em: 20 mar. 2015.

EICHLER. B.; LEMOS, A. H. C; NEVES, D. R. Contrato Psicológico de Funcionários de Empresas Públicas Egressos do Setor Privado: Como se Constrói essa Relação? In: ENANPAD, 38., 2014, Rio de Janeiro. Anais... Rio de Janeiro, 2014.

ERICKSON, T. Plugged in: the generation Y guide to thriving at work. Boston: Harvard Business Press, 2008.

KILIMNIK, Z. M.; OLIVEIRA, L. C. V.; CORRÊA, M. L. R. Transição da gerência para a docência: estratégias de carreira e competências. In: SEMINÁRIO DE PESQUISA E EXTENSÃO FUMEC, 6., 2009, Belo Horizonte. Anais... Belo Horizonte, 2009.

LEMOS, A. H. da C. Juventude, Gerações e Trabalho: Ampliando o Debate. Organização \& Sociedade, v. 19, n. 63, p. 739-743, out./dez. 2012.

LIPKIN, N. A.; PERRYMORE, A. J. A geração Y no trabalho: como lidar com a força de trabalho que influenciará definitivamente a cultura de sua empresa. Rio de Janeiro: Elsevier, 2010.

MINISTÉRIO DO TRABALHO. Disponível em: <http://portal.mte.gov.br/imprensa/ministro-abre-i-seminario-sobre-rotatividade-no-mercado-de-trabalho.htm>. Acesso em: 21 mar. 2015. 
MORIN, E. M. Os sentidos do trabalho. Revista de Administração de Empresas, v. 41, n. 3, p. 9, 2001.

MORIN, E. M.; TONELLI, M. J.; PLIOPAS, A. L. V. O Trabalho e Seus Sentidos. Revista Psicologia \& Sociedade, v. 19, 2007.

MOW. International Research Team. The meaning of work. Washington, DC: Academy Press, 1987.

OLIVEIRA, S. R. et al. Buscando o sentido do trabalho. In: ENANPAD, 28., 2004, Curitiba. Anais... Curitiba, 2004.

OLIVEIRA, L. C. V.; KILIMNIK, Z. M.; DE OLIVEIRA, R. P. Da gerência para a docência: metáforas do discurso de transição. Revista Eletrônica de Administração, v. 19, i. 2, p. 301-329, 2013.

OLIVEIRA, S. O.; PICCININI, V. P.; BITENCOURT, B. M. Juventude, Gerações e Trabalho: É Possível Falar em Geração Y no Brasil? Organização \& Sociedade, v. 19, n. 62, p. 551-558, jul./set. 2012.

PERRONE, C. M. et al. A percepção das organizações pela Geração Y. Revista de Administração da UFSM, v. 6, n. 3, p. 546-560, 2013.

ROSSO, B. D.; DEKAS, K. H.; WRZESNIEWSKI, A. On the meaning of work: A theoretical integration and review. Research in organizational behavior, v. 30, p. 91-127, 2010.

SÁ, P. F.; LEMOS, A. H. da C.; CAVAZOTTE, F. S. C. N. Expectativas de carreira na contemporaneidade: o que querem os jovens profissionais? Revista ADM. MADE, v. 14, n. 2, p. 8-27, maio/ago. 2014.

SILVA, J. Profissionais qualificados e experiência de autoemprego: questões de tempo e espaço. Revista Eletrônicade Administração, v. 14, n. 1, 2008.

SMOLA, K. W.; SUTTON, C. D. Generational differences: revisiting generational work values for the new millennium. Journal of Organizational Behavior, v. 23, n. 4, 2002.

TEIXEIRA, A. P. P. et al. O sentido do trabalho: uma análise à luz das gerações XEY. Diálogo, v. 25, p. 25, 2014. 
TOLFO, S. R.; PICCININI, V. C. Sentidos e significados do trabalho: explorando conceitos, variáveis e estudos empíricos brasileiros. Psicologia \& Sociedade, v. 19, n. 1, p. 38-46, 2007.

TULGAN, B. Not Everyone Gets a Trophy - How to Manage Generation Y. São Francisco: Jossey-Bass, 2009.

VASCONCELOS, K. C. et al. A Geração Y e suas âncoras de carreira. Revista Eletrônica de Gestão Organizacional, v. 8, n. 2, 2010.

VELOSO, E. F. R.; SILVA, R. C. D.; DUTRA, J. S. Diferentes gerações e percepções sobre carreiras inteligentes e crescimento profissional nas organizações. Revista Brasileira de Orientação Profissional, v. 13, n. 2, p. 197-208.

\section{Como citar este artigo:}

\section{ABNT}

LEMOS, Ana Heloisa da Costa; PINTO, Mariana Soares Pinto; SILVA, Marcelo Almeida de Carvalho. Mal-estar nas organizações: por que os jovens estão abandonando o mundo corporativo? RACE, Revista de Administração, Contabilidade e Economia, Joaçaba: Ed. Unoesc, v. 16, n. 2, p. 703-728, maio/ago. 2017. Disponível em: <http://editora.unoesc.edu.br/index.php/race>. Acesso em: dia/mês/ano.

APA

Lemos, A. H. da C., Pinto, M. S. P., \& Silva, M. A. de C. (2017). Mal-estar nas organizações: por que os jovens estão abandonando o mundo corporativo? RACE, Revista de Administração, Contabilidade e Economia, 16(2), 703-728. Recuperado em dia/mês/ano, de http://editora.unoesc.edu.br/index.php/race 